\title{
Preface - How much are the keywords worth?
}

\author{
T. Czigány*
}

Department of Polymer Engineering, Faculty of Mechanical Engineering, Budapest University of Technology and Economics, Müegyetem rkp. 3., H-1111, Budapest, Hungary

\section{Dear Readers,}

You are reading the first issue of the eighth volume of eXPRESS Polymer Letters. Number 8 has traditionally been the number of luck and fulfilment (eight lives were saved in the ark of Noah: he, his wife, his three sons and their wives). This volume will be decisive in the life of our journal as well, as the impact factor, the recognition and popularity of eXPRESS Polymer Letters increases continuously. With our present impact factor of 2.294 we are in the first third of all journals worldwide, not only within our field of interest. Our aim for this year is to get into the best $25 \%$, which is a kind of elite club. Readership and authorship of $\boldsymbol{e X P R E S S ~ P o l y m e r ~ L e t t e r s ~}$ is progressively increasing, meaning a great responsibility and hard work for the editors and the Editorial Board as they are the gate keepers whose concerns is to allow only the publication of possibly best quality articles dealing with cutting edge topics. Therefore the peer reviewing process was made even stricter, presently $82 \%$ of the submitted manuscripts are rejected, but this does not mean a slower publishing procedure.

Investigating the keywords of the articles published so far in eXPRESS Polymer Letters the first ten most frequently used ones are as follows: polymer composites; nanocomposites; mechanical properties; thermal properties; nanomaterials; biodegradable polymers; polymer synthesis and molecular engineering; smart polymers; polymer blends and alloys; biopolymers and biocomposites. These reflect well the actual $\mathrm{R} \& \mathrm{D}$ directions in the world, being mostly application and industry-oriented, which is of course acceptable, as research is not made for itself. But it may be also noted that one of the negative effects of the economic crisis is that project funding can hardly be

\footnotetext{
${ }^{*}$ Corresponding author, e-mail: czigany@eik.bme.hu (C) BME-PT
}

won for basic research, supporting bodies are inclined to give support for applied research promising faster return. On the other hand it is not to be forgotten that applied research is always preceded by basic research (nowadays termed as exploratory research), which in fact rarely results in direct practical utilization. Another observed tendency is that the keywords of the project applications influence more the acceptance of the project than the content of the project. The term 'nano' became a popular keyword in science in all kinds of combinations and it was nearly impossible to get grants without this almighty expression being present in every second sentence. Sometimes one wonders, how many things appear under the 'nano' umbrella not recognized as such before ... Among the current popular keywords, one of the widest is 'bio' which suggests natural character in all kinds of combinations. As the selection of proper keywords may influence not only the evaluation of an article but also the amount of funding received, it is advisable to maintain a good balance of them.

In the New Year I wish a successful keyword selection for each author and reader of $\boldsymbol{e X P R E S S}$ Polymer Letters and I would like to take the opportunity to congratulate the chief editor of our journal, Professor Karger-Kocsis on the occasion that his citation reached the desired limit of ten thousand. Sincerely yours,

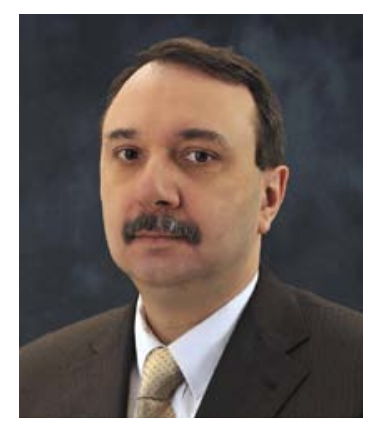

Prof. Dr. Tibor Czigány, editor 